\title{
Esophageal Perforation Due to Endoscopic Retrograde Cholangiopancreatography
}

Esophageal perforation is a significant complication in upper gastrointestinal endoscopy. Bacteria and digestive enzymes can easily reach the mediastinum, and complications leading to death, such as mediastinal abscess and sepsis, can develop (1).

A 65-year-old man was referred to our clinic with jaundice, malaise, itching and weight-loss. He had been suffering these complaints for six months. On physical examination, the skin was found to be icteric, and the gallbladder was deeply palpated without tenderness. The pancreatic mass was demonstrated by endoscopic retrograde cholangiopancreatography (ERCP). During the ERCP, a 10-Fr stent was inserted into the common bile duct. After ERCP, the patient suffered mild dysphagia and retrosternal pain after meals. On contrast radiography, the meal was seen to be collecting outside the distal part of the esophagus as a second lumen (Figure 1). Computed tomography of the chest showed a cystic lesion in the back thyroidal region and air-fluid levels on the back of the atrium (Figure 2). In view of 


\section{Unusual Cases and Technical Notes s3}

the patient's esophageal perforation, a nasoenteral tube was inserted, and antibiotic therapy was started. As no complications were observed, the feeding tube was taken out after four weeks. He tolerated oral nutrition and was discharged.

Upper gastrointestinal endoscopy (GIS) is the most reliable procedure, with a complication rate of $0.1 \%$ and a mortality rate below $0.005 \%$. $(1,2)$. Many authors consider that the risk of perforation in therapeutic interventions is higher than in diagnostic ones (3). ERCP is an unusual cause of esophageal perforation. Whatever the cause is, delay in diagnosing perforation increases the risk of morbidity and mortality $(3,4)$. One should bear in mind that perforations related to ERCP procedures may occur, even if they may be rare.

A. Tezel, T. Şahin, Y. Koşar, D. Oğuz,

B. Şahin, T. Cumhur

Dept. of Gastroenterology,

Dept. of Radiology,

Yüksek Ihtisas Hospital,

Ankara, Turkey

\section{References}

1. Pasricha P, Fleisher D, Kalloo A. Endoscopic perforations of the upper digestive tract. A review of their pathogenesis, prevention and management. Gastroenterology 1994; 106: 787-802.

2. Hart R, Classen M. Complications of diagnostic gastrointestinal endoscopy. Endoscopy 1990; 22: 229-33.

3. Kim-Deobald J, Kozarek R. Esophageal perforation: an 8-year review of a multispecialty clinic's experience. Am J Gastroenterol 1992; 87: 1112-9.

4. Sawyer R, Philips C, Vakil N. Shortand long-term outcome of esophageal perforation. Gastrointest Endosc 1995; 41: $130-4$.

Corresponding Author

A. Tezel, M.D.

Atakoey 5. Kisim

E 2-3 A Kapisi-9

Istanbul

Turkey

Tel.: +90-312-2405927

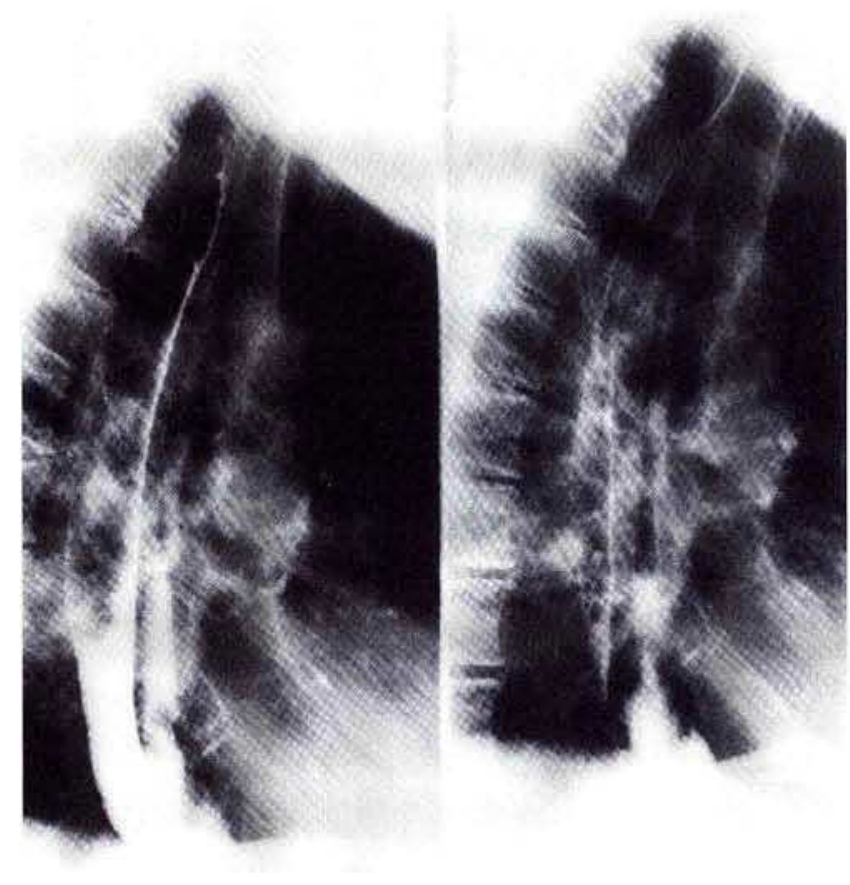

Figure 1: The barium meal is seen collecting as a second lumen outside the esophagus.

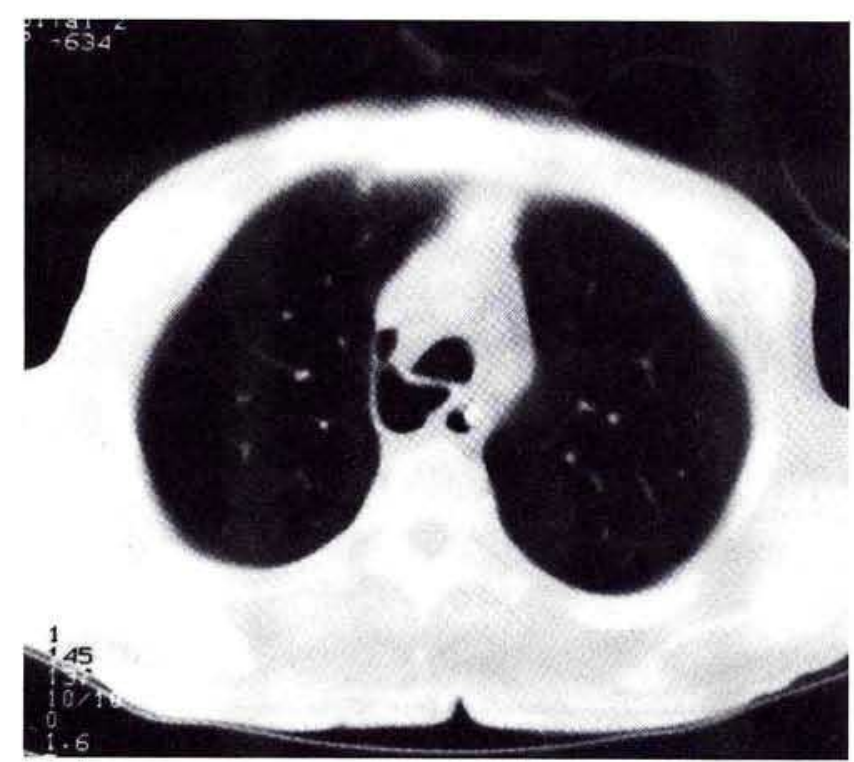

Figure 2: Computed tomography showing air in the mediastinum. 